\title{
Herediter ve Ailesel Meme Kanserlerinin Aile Öyküsüi ile Klinikopatolojik Özelliklerinin Karşılaştırılması; Tek Merkez Deneyimi
}

\section{Comparison of Family History and Clinicopathological Features of Hereditary and Familial Breast Cancers; Single Center Experience}

\author{
Kayhan Özdemir ${ }^{1}$, Merve Yiğit ${ }^{1}$, Yasemin Anıl Eyüboğlu Tanrıverdi ${ }^{2}$, Mine Urfalı ${ }^{2}$, Belma Koçer ${ }^{1}$ \\ ${ }^{1}$ Sakarya Üniversitesi Tip Fakültesi, Genel Cerrahi Anabilim Dalı, Sakarya \\ ${ }^{2}$ Sakarya Üniversitesi Eğitim Araştırma Hastanesi Tibbi Genetik, Sakarya \\ Yazışma Adresi / Correspondence:
}

Kayhan Özdemir

Şirinevler Mahallesi Adnan Menderes Caddesi Sağlık Sokak No:195 / 54100 Adapazarı Sakarya

T: +90553 3800289 E-mail : Drkayhan1@gmail.com

Geliş Tarihi / Received : 07.05.2021 Kabul Tarihi / Accepte: 07.09.2021

Orcid :

Kayhan Özdemir https://orcid.org/0000-0002-8041-198X

Merve Yiğit https://orcid.org/0000-0001-5217-9629

Yasemin Anıl Eyüboğlu Tanrıverdi https://orcid.org/0000-0002-6521-7767

Havva Belma Koçer https://orcid.org/0000-0002-9888-0661

Mine Urfalı https://orcid.org/0000-0002-9232-2220

( Sakarya Tip Dergisi / Sakarya Med J 2021, 11(3):647-653) DOI: 10.31832/smj.934186

\begin{tabular}{|c|c|}
\hline \multicolumn{2}{|l|}{$\ddot{O} z$} \\
\hline Amaç & $\begin{array}{l}\text { Meme kanseri kadınlarda en sık teşhis edilen kanserdir. Sporadik meme kanserlerinden sonra en sık ailesel ardından herediter meme kanserleri gelir. Çalışmamızda } \\
\text { herediter ve ailesel meme kanserlerinin klinikopatolojik özelliklerini kıyaslamayı amaçladık. }\end{array}$ \\
\hline $\begin{array}{l}\text { Gereç ve } \\
\text { Yöntemler }\end{array}$ & $\begin{array}{l}\text { Sakarya Üniversitesi Eğitim ve Araştırma Hastanesinde 2019-2020 yılları arasında tanı konulan meme kanseri olgularında aile hikayesi ve patolojik özellikler göz önünde } \\
\text { bulundurularak genetik test yapılan hastaların verileri retrospektif tarandı. }\end{array}$ \\
\hline Bulgular & $\begin{array}{l}\text { Herediter ve ailesel meme kanserli olgular karşlaştırıldığında herediter meme kanserli hastaların tanıda daha ileri evre oldukları, yüksek Ki- } 67 \text { indeksine sahip oldukları } \\
\text { ve reseptör negatif oldukları saptandı.BRCAl mutasyonlu olgularda ise BRCA2'ye göre tanıda yüksek histolojik evre, artmış metastatik lenf nodu ve reseptör negatifliği } \\
\text { görüldü. }\end{array}$ \\
\hline Sonuç & $\begin{array}{l}\text { BRCA (Breast Cancer Gene) mutasyonu olan tümörlerin ailesel geçişli meme kanserli hastalara göre daha agresif, BRCA1 mutasyonu olan tümörler ise BRCA2 mutasyonu } \\
\text { olan tümörlere göre daha agresif tümörler olduğunu saptadık. Kuvvetli aile öyküsü olan veya herediter meme kanseri șüpheli olgularda erken dönemde genetik danışmanlık } \\
\text { desteği alınmalıdır. Bu mutasyonların saptanması hastaların cerrahi ve medikal tedavisinde farklıllklar sebep olacaktır. }\end{array}$ \\
\hline $\begin{array}{r}\text { Anahtar } \\
\text { Kelimeler }\end{array}$ & Meme kanseri; Ailesel; Herediter \\
\hline \multicolumn{2}{|l|}{ Abstract } \\
\hline Objective & $\begin{array}{l}\text { Breast cancer is the most frequently diagnosed cancer in women. The most common after sporadic breast cancers is familial followed by hereditary breast cancers. We aimed to compare the } \\
\text { clinicopathological characteristics of hereditary and familial breast cancers. }\end{array}$ \\
\hline $\begin{array}{r}\text { Materials } \\
\text { and Methods }\end{array}$ & The patients who underwent genetic testing were screened considering the risks in breast cancer cases diagnosed between 2019-2020 at Sakarya University Education and Research Hospital. \\
\hline Resulrs & $\begin{array}{l}\text { When cases with hereditary and familial breast cancer were compared, it was found that patients with hereditary breast cancer were at a more advanced stage in diagnosis, had a high Ki-67 } \\
\text { index and were receptor negative.In cases with BRCA1 mutation, higher histological grade, increased metastatic lymph node and receptor negativity were observed in the diagnosis according } \\
\text { to BRCA2. }\end{array}$ \\
\hline Conclusion & $\begin{array}{l}\text { We found that tumors with BRCA (Breast Cancer Gene) mutations are more aggressive than patients with familial inherited breast cancer, and tumors with BRCA1 mutations are more aggres- } \\
\text { sive than tumors with BRCA2 mutations.Early genetic counseling support should be obtained in cases with a family history or suspected hereditary breast cancer. Detection of these mutations } \\
\text { will cause differences in surgical and medical treatment of patients. }\end{array}$ \\
\hline Keywords & Breast cancer; Familial; Hereditary \\
\hline
\end{tabular}




\section{GIIRIŞ}

Kadınlar arasında meme kanseri en sık teşhis edilen kanserdir. Uluslararası Kanser Araştırma Ajansı tarafından üretilen GLOBOCAN 2018 kanser insidansı ve mortalite verilerine göre 2018'de tahminen 18,1 milyon yeni kanser vakası ve 9,6 milyon kansere bağlı ölüm görülmüştür. Kansere bağlı ölümlerde tüm kanserler içerisinde meme kanseri ikinci sıradadır $(\% 11,6) .{ }^{1}$ Meme kanserinde aile öyküsünün olması değiştirilemeyen risk faktörlerinden biridir. Yaştan sonra ikinci en sık predispozan faktördür. Meme kanserlerinin \%5-10'u kalıtsaldır ve çoğu BRCA-1 ve BRCA-2 gen mutasyonuna bağlıdır. Ailesel meme kanserleri ise $\% 20-25$ görülmektedir. ${ }^{2}$

BRCA geni 1990'ların ortalarından beri kapsamlı araştırma konusu olmuştur. BRCA1/2 tümör baskılayıcı rolleriyle bilinir ve DNA çift sarmal hasarlarının onarımını, genomik stabiliteyi, hücre döngüsünün ilerlemesini düzenleyen biyolojik yolları, transkripsiyonel regülasyonu, apopitozu, kromatini yeniden modellemeyi, hücre büyümesini ve homologu düzenlemede etkili oldukları gösterilmiştir. ${ }^{3,4}$

BRCA1/2 otozomal dominant geçişlidir ve yaygınlıkları farklı popülasyonlar arasında farklılık göstermektedirler. ${ }^{5}$ BRCA1/2 patojenik varyantlarının genel popülasyondaki prevalansı yaklaşık 1: 400 ila 1: 500 olarak tahmin edilmektedir. ${ }^{6}$ BRCA mutasyonuna sahip kadınlarda 70 yaşına kadar meme kanseri gelişme olasılığ BRCA-1'de \%60-85, BRCA-2'de \%70-84'tür'. Bu mutasyon taşıyıcıları kontralateral meme, over ve fallop tüpü kanserlerinin gelişmesi açısından da yüksek risk altındadır. ${ }^{8}$

Herediter meme kanserlerinde aile öyküsü her zaman olmayabilir. Ailesel meme kanserlerinin sadece \%25'inde BRCA gen mutasyonu saptanmıştır. ${ }^{9}$ Ailede meme kanseri öyküsü olan yüksek risk altındaki hastalarda, negatif mutasyon taraması durumunda kalıtsal hastalığa işaret eden ek özellikler değerlendirilmelidir. Aile öyküsüne göre orta derecede kalıtsal hastalık riski taşıyan hastalarda, ek özellikler mutasyon taramasına karar vermeye yardımcı olabilir. Tersine, bu tür özellikler şüpheli bir aile öyküsü olması durumunda mutasyon taraması ihtiyacını ortadan kaldırabilir.

BRCA1 ile ilgili meme kanserlerinde; genç yaş, kötü diferansiye tümör, yüksek proliferasyon, östrojen reseptör negatifliği, p53 ve HER-2/neu pozitifliği, epidermal büyüme faktörü reseptörünün (EGFR) aşırı ekspresyonu görülebilir. ${ }^{10,11}$ BRCA2 ile ilgili tümörler nispeten daha az özgün klinikopatolojik bulgular gösterirler ve genellikle östrojen reseptör pozitiftirler. Literatürde sınırlı sayıda çalışmada herediter ve ailesel meme kanserleri ayrı kategorize edilmiş ve bunların klinikopatolojik özellikleri kıyaslanmıştir. $^{12,13}$

Çalışmamızda BRCA1/2 gen mutasyonuna sahip herediter meme kanserleri ile bu mutasyona sahip olmayan ailesel meme kanseri tanılı hastaların klinikopatolojik özelliklerini karşılaştırmayı amaçladık.

\section{GEREÇ ve YÖNTEMLER}

Çalışmamız Sakarya Üniversitesi Tip Fakültesi Girişimsel Olmayan Klinik Araştırmalar Etik Kurulu 29.01.2021 tarihli E-71522473-050.01.04.605836 sayılı onayı ile Helsinki Deklarasyonuna uyularak yapılmıştır.

Kurumumuzda 2019-2020 yılları arasında tanı konulan meme kanseri olgularında herediter ve ailesel riskler göz önünde bulundurularak genetik test yapilanlar incelendi. Genetik teste uygunluğuna National Comprehensive Cancer Network (NCCN) kılavuzu referans alınarak karar verildi. ${ }^{14}$ Testi pozitif sonuçlanan olguların, sağlıklı birinci derece akrabalarına da genetik test yaptırmaları önerildi. Saptanan kalıtsal ve ailesel meme kanserli olgularda; yaş, tümör çapı, klinik evre, patolojik evre, metastatik lenf nodu varlığı, histolojik grade, lenfatik invazyon, vasküler invazyon, hormon reseptörleri, Ki-67 indeksleri incelendi. Neoadjuvan kemoterapi tedavisi alan olgularda ise bunlara ek olarak; tanıda metastatik lenf nodu varlığı, tümör ve aksillanın kemoterapiye yanıtı, Miller Payne sınıflandırması, 
lenf nodu regresyonu varlığg analiz edildi.

Veriler SPSS 23.0 programı kullanılarak analiz edildi. Sonuçların homojenite testi için Kolmogorov-Smirnov kullanıldı. Korelasyon testi için Spearman's korelasyon testi kullanılırken, kategorik değişkenler arasındaki anlamlılığı analiz etmek için Ki-kare testi kullanıldı. Bağımsız gruplar arasındaki farklılıkları incelemek için Mann-Whitney U testi uygulandı. $\mathrm{p}<0.05$ anlamlı kabul edildi.

\section{BULGULAR}

Sakarya Üniversitesi Eğitim Araştırma Hastanesi Genel Cerrahi Kliniği'nde 2019-2020 yılları arasında meme kanseri tanısı konulan 272 hastadan 43 'ünde $(\% 15,8)$ genetik test endikasyonu mevcuttu. Bu hastalardan 13'üne (\%30,2) BRCA pozitif meme kanseri tanısı konuldu. Otuz hastada ise ailesel meme kanseri görüldü $(\% 69,8)$.

BRCA pozitif grupta yaş ortalaması 44,6y (29-62) iken negatif grupta 41y (27-61) idi. Anlamlı farklılık saptanmadı. Tanı anındaki klinik evreler karşılaştırıldığında BRCA pozitif hastaların negatif hastalara oranla daha ileri evrede tanı aldıkları görüldü $(\mathrm{p}=0,030)$. Bu mutasyona sahip tümörlerin daha yüksek Ki-67 indeksine sahip oldukları görüldü $(\mathrm{p}=0,010)$. BRCA pozitif hastalarda hormon reseptör negatiflik sıklığının daha yüksek olduğu saptandı. BRCA (+) olgularda ER (+) ve PR (+)'liği \%30.8 iken, BRCA (-) olgularda ER (+)'liği \%83.3 (p=0.010), PR (+) ise \%73.3 $(\mathrm{p}<0,01)$ olarak saptanmıştır. Neoadjuvan kemoterapi alan olgularda Miller Payne evrelemesine göre tam yanıt oranları BRCA mutasyonu olan hastalarda daha fazla olduğu görüldü.

BRCA mutasyonu pozitif grupla negatif grup arasında; tanı anındaki tümör çapları, metastatik lenf nodu varlığı, histolojik grade, patolojik evre, komplet yanıt, lenfatik ve vasküler invazyon varlığı ile neoadjuvan kemoterapi alan hastalardaki lenf nodu regresyonu oranları arasında anlamlı farklılık saptanmadı (Tablo 1).
BRCA1 ve BRCA2 mutasyonları saptanan hastaların klinikopatolojik parametreleri karşılaştırıldığında ise BRCA1 pozitif hastaların daha ileri evrede tanı aldığını ( $\mathrm{p}=0,030)$ ve BRCA2 pozitif hastalara göre anlamlı şekilde artmış lenf nodu metastazları varlığının olduğu görüldü $(\mathrm{p}=0,040)$. BRCA1 pozitif olgularda BRCA2 pozitif olgulara göre reseptör negatifliğini daha fazla olduğunu ve daha yüksek histolojik dereceye sahip olduğu saptandı $(\mathrm{p}=0,050)$ (Tablo 2).

\section{TARTIŞMA}

Ailede meme kanseri öyküsünün olması kalıtsal meme kanserinde de bir risk faktörü olarak değerlendirildiğinden herediter ve ailesel meme kanserleri birbirleriyle sıklıkla karışabilmektedir. Ailede meme kanseri öyküsü olan hastalarda meme kanserinin yönetimi ve sürveyansı konusundaki tartışmalar ise halen devam etmektedir. ${ }^{15,16,17}$

Genel olarak herediter meme kanserlerinin daha yüksek evreye sahip, reseptör negatif ve agresif özelliklere sahip olduğu bildirilmektedir. ${ }^{18-20}$ Van der Groep ve arkadaşlar1nın sporadik, ailesel ve herediter meme kanserlerinin klinikopatolojik özelliklerini kıyasladıkları çalışmada; ailesel meme kanserleriyle sporadik meme kanserlerinin klinik özellikleri arasında anlamlı bir farktan söz edilmezken; BRCA1 mutasyonuna sahip tümörlerde hormon reseptör seviyelerinin düşük, Ki-67 indeksi ile tümörün histolojik derecesinin ise yüksek olduğu gösterilmiştir. ${ }^{21}$

Çalışmamızda da BRCA pozitif herediter meme kanserli olgularda ailesel meme kanserli olgulara göre daha agresif tümör özellikleri olan; hormon reseptör negatifliği, yüksek Ki-67 indeksiyle beraber düşük kemoterapi yanıtı saptanmiştır.

Baretta ve arkadaşlarının 3588 BRCA mutasyon taşıyıcısı içeren meta-analizinde, BRCA1 ile ilişkili meme kanseri olgular yüksek histolojik grade ve triple negatif özellikler göstermektedir. BRCA2 ile ilişkili meme kanseri ise, sporadik vakalardan ortalama olarak daha yüksek histolojik 
Sakarya Tip Dergisi 2021;11(3):647-653

ÖZDEMIR ve Ark., Herediter ve Ailesel Meme Kanserlerinin Kıyaslanması

\begin{tabular}{|c|c|c|c|c|c|}
\hline \multicolumn{2}{|c|}{ Klinikopatolojik Parametreler } & $\mathrm{n}(\%)$ & $\operatorname{BRCA}(+)$ & BRCA (-) & $\mathrm{P}$ \\
\hline \multirow{2}{*}{ Yaş } & $<50$ & $34(79,1)$ & $8(61,5)$ & $26(86,7)$ & \multirow{2}{*}{$\mathrm{P}=0,060$} \\
\hline & $>50$ & $9(20,9)$ & $5(38,5)$ & $4(13,3)$ & \\
\hline \multirow{2}{*}{ Tanı tümör çapı } & $\mathrm{T} 1$ & $21(48,8)$ & $7(53,8)$ & $14(46,7)$ & \multirow{2}{*}{$\mathrm{P}=0,660$} \\
\hline & $\mathrm{T} 2$ & $22(51,2)$ & $6(46,2)$ & $16(53,3)$ & \\
\hline \multirow{3}{*}{ Klinik evre } & 1 & $12(27,9)$ & $5(38,5)$ & $7(23,3)$ & \multirow{3}{*}{$\mathrm{P}=0,030$} \\
\hline & 2 & $29(67,4)$ & $6(46,2)$ & $23(76,7)$ & \\
\hline & 3 & $2(4,7)$ & $2(15,4)$ & $0(0)$ & \\
\hline \multirow{2}{*}{ Metastatik LN } & Yok & $27(62,8)$ & $9(69,2)$ & $18(60)$ & \multirow{2}{*}{$\mathrm{P}=0,560$} \\
\hline & Var & $16(37,2)$ & $4(30,8)$ & $12(40)$ & \\
\hline \multirow{3}{*}{ Histolojik grade } & 1 & $5(18,5)$ & $0(0)$ & $5(23,8)$ & \multirow{3}{*}{$\mathrm{P}=0,370$} \\
\hline & 2 & $13(48,1)$ & $4(66,7)$ & $9(42,9)$ & \\
\hline & 3 & $9(33,3)$ & $2(33,3)$ & $7(33,3)$ & \\
\hline \multirow{2}{*}{ Vasküler invazyon } & Yok & $34(79,1)$ & $11(84,6)$ & $23(76,7)$ & \multirow{2}{*}{$\mathrm{P}=0,550$} \\
\hline & Var & $9(20,9)$ & $2(15,4)$ & $7(23,3)$ & \\
\hline \multirow{2}{*}{ Lenfatik invazyon } & Yok & $33(76,7)$ & $9(69,2)$ & $24(80)$ & \multirow{2}{*}{$\mathrm{P}=0,440$} \\
\hline & Var & $10(23,3)$ & $4(30,8)$ & $6(20)$ & \\
\hline \multirow{2}{*}{ ER } & Negatif & $14(32,6)$ & $9(69,2)$ & $5(16,7)$ & \multirow{2}{*}{$\mathrm{P}=0,010$} \\
\hline & Pozitif & $29(67,4)$ & $4(30,8)$ & $25(83,3)$ & \\
\hline \multirow{2}{*}{ PR } & Negatif & $17(39,5)$ & $9(69,2)$ & $8(26,7)$ & \multirow{2}{*}{$\mathrm{P}=0,000$} \\
\hline & Pozitif & $26(60,5)$ & $4(30,8)$ & $22(73,3)$ & \\
\hline \multirow{2}{*}{ Cerb2 } & Negatif & $34(79,1)$ & $11(84,6)$ & $23(76,7)$ & \multirow{2}{*}{$\mathrm{P}=0,550$} \\
\hline & Pozitif & $9(20,9)$ & $2(15,4)$ & $7(23,3)$ & \\
\hline \multirow{3}{*}{$\mathrm{Ki}-67$} & $<14$ & $13(36,1)$ & $1(8,3)$ & $12(50)$ & \multirow{3}{*}{$\mathrm{P}=0,010$} \\
\hline & $14-30$ & $11(30,6)$ & $7(58,3)$ & $4(16,6)$ & \\
\hline & $>30$ & $12(33,3)$ & $4(33,3)$ & $8(33,3)$ & \\
\hline \multirow{2}{*}{$\begin{array}{l}\text { Lenf nodu regre- } \\
\text { syonu }\end{array}$} & Yok & $13(59,1)$ & $5(83,3)$ & $8(50)$ & \multirow{2}{*}{$\mathrm{P}=0,150$} \\
\hline & Var & $9(40,9)$ & $1(16,7)$ & $8(50)$ & \\
\hline \multirow{2}{*}{$\begin{array}{l}\text { Hem tümör hem } \\
\text { aksilla } \\
\text { yanitı }\end{array}$} & Yok & $13(59,1)$ & $4(66,6)$ & $9(56,3)$ & \multirow{2}{*}{$\mathrm{P}=0,650$} \\
\hline & Var & $9(40,9)$ & $2(33,3)$ & $7(43,7)$ & \\
\hline \multirow{2}{*}{ Komplet Yanit } & Yok & $13(59,1)$ & $3(50)$ & $10(62,5)$ & $D^{D}=0 \% 0$ \\
\hline & Var & $9(40,9)$ & $3(50)$ & $6(37,5)$ & $1-0,300$ \\
\hline & 0 & $10(23,8)$ & $2(16,7)$ & $8(26,7)$ & \\
\hline Patoloiil evro & 1 & $10(23,8)$ & $4(33,3)$ & $6(20)$ & 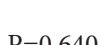 \\
\hline Talotojis evic & 2 & $14(33,3)$ & $3(25)$ & $11(36,7)$ & $1-0,040$ \\
\hline & 3 & 8 (19) & $3(25)$ & $5(16,7)$ & \\
\hline
\end{tabular}


Sakarya Tip Dergisi 2021;11(3):647-653

ÖZDEMIR ve Ark., Herediter ve Ailesel Meme Kanserlerinin Kiyaslanması

\begin{tabular}{|c|c|c|c|c|c|}
\hline \multicolumn{2}{|c|}{$\begin{array}{l}\text { BRCA Mutasyonlu Olguların } \\
\text { Klinikopatolojik Parametreleri }\end{array}$} & $\mathrm{n}(\%)$ & BRCA 1 & BRCA 2 & $\mathrm{P}$ \\
\hline \multirow{2}{*}{ Yaş } & $<50$ & $8(79,1)$ & $5(62,5)$ & $3(60)$ & \multirow{2}{*}{$\mathrm{P}=0,920$} \\
\hline & $>50$ & $5(20,9)$ & $3(37,5)$ & $2(40)$ & \\
\hline \multirow{2}{*}{ Tanı tümör çapı } & $\mathrm{T} 1$ & $7(53,8)$ & $3(37,5)$ & $4(80)$ & \multirow{2}{*}{$\mathrm{P}=0,130$} \\
\hline & $\mathrm{T} 2$ & $6(46,2)$ & $5(62,5)$ & $1(20)$ & \\
\hline \multirow{3}{*}{ Klinik evre } & 1 & $5(38,5)$ & $3(37,5)$ & $2(40)$ & \multirow{3}{*}{$\mathrm{P}=0,030$} \\
\hline & 2 & $6(46,1)$ & $3(37,5)$ & $3(60)$ & \\
\hline & 3 & $2(15,4)$ & $2(25)$ & $0(0)$ & \\
\hline \multirow{2}{*}{ Metastatik LN } & Yok & $9(69,2)$ & $4(50)$ & $5(100)$ & \multirow{2}{*}{$\mathrm{P}=0,040$} \\
\hline & Var & $4(30,8)$ & $4(50)$ & $0(0)$ & \\
\hline \multirow{3}{*}{ Histolojik grade } & 1 & $2(15,4)$ & $0(0)$ & $2(40)$ & \multirow{3}{*}{$\mathrm{P}=0,050$} \\
\hline & 2 & $7(53,8)$ & $4(50)$ & $3(60)$ & \\
\hline & 3 & $4(30,8)$ & $4(50)$ & $0(0)$ & \\
\hline \multirow{4}{*}{ Patolojik evre } & 0 & $2(16,7)$ & $1(8,3)$ & $1(20)$ & \multirow{4}{*}{$\mathrm{P}=0,370$} \\
\hline & 1 & $4(33,3)$ & $2(16,7)$ & $2(40)$ & \\
\hline & 2 & $3(25)$ & $1(8,3)$ & $2(40)$ & \\
\hline & 3 & $3(25)$ & $3(25)$ & $0(0)$ & \\
\hline \multirow{2}{*}{ Vasküler invazyon } & Yok & $11(84,6)$ & $6(75)$ & $5(100)$ & \multirow{2}{*}{$\mathrm{P}=0,220$} \\
\hline & Var & $2(20,9)$ & $2(25)$ & $0(0)$ & \\
\hline \multirow{2}{*}{ Lenfatik invazyon } & Yok & $9(69,2)$ & $5(62,5)$ & $4(80)$ & \multirow{2}{*}{$\mathrm{P}=0,560$} \\
\hline & Var & $4(30,8)$ & $3(37,5)$ & $1(20)$ & \\
\hline \multirow{2}{*}{ ER } & Negatif & $9(69,2)$ & $7(87,5)$ & $2(40)$ & \multirow{2}{*}{$\mathrm{P}=0,050$} \\
\hline & Pozitif & $4(30,8)$ & $1(12,5)$ & $3(60)$ & \\
\hline \multirow{2}{*}{ PR } & Negatif & $9(69,2)$ & $7(87,5)$ & $2(40)$ & \multirow{2}{*}{$\mathrm{P}=0,050$} \\
\hline & Pozitif & $4(30,8)$ & $1(12,5)$ & $3(60)$ & \\
\hline \multirow{2}{*}{ Cerb2 } & Negatif & $11(84,6)$ & $7(87,5)$ & $4(80)$ & \multirow{2}{*}{$\mathrm{P}=0,710$} \\
\hline & Pozitif & $2(15,4)$ & $1(12,5)$ & $1(20)$ & \\
\hline \multirow{3}{*}{$\mathrm{Ki}-67$} & $<14$ & $1(8,3)$ & $1(14,3)$ & $0(0)$ & \multirow{3}{*}{$\mathrm{P}=0,390$} \\
\hline & $14-30$ & $7(58,3)$ & $3(42,9)$ & $4(80)$ & \\
\hline & $>0$ & $4(33,3)$ & $3(42,9)$ & $1(20)$ & \\
\hline
\end{tabular}


derecelidir. BRCA mutasyonuna sahip hastaların sporadik gruba göre kötü prognoza sahip olduklarını saptanmıştır. ${ }^{22}$ Zhu ve arkadaşlarının yaptığı bir başka meta-analizde ise BRCA1 mutasyonuna sahip hastalar hormon reseptör negatif tümörler, BRCA2 mutasyonuna sahip hastalarda ise yüksek tümör histolojik derecesi saptanmıştır. ${ }^{23}$

Eerola ve arkadaşlarının yaptığı çalışmada ise BRCA1 mutasyonuna sahip tümörlerin BRCA2 mutasyonuna sahip hastalara ve ailesel meme kanserli hastalarda göre daha kötü prognoza sahip olduğunu belirtilmiş ancak istatistiksel olarak anlamlandırılamamıştır. ${ }^{24}$

Çalışmamızda ise; BRCA1 mutasyonuna sahip tümörlerin BRCA2 mutasyonuna sahip tümörlere göre lenf nodu metastaz oranlarının daha fazla olduğunu, ileri klinik evre, yüksek histolojik grade sahip olduklarını ve hormon reseptörlerinin sıklıkla negatif olduğunu saptadık. Hasta sayımız az olmasına rağmen literatür sonuçları ile uyumlu olarak BRCA mutasyonu olan tümörlerin ailesel geçişli meme kanserli hastalara göre daha agresif özelliklere sahip olduklarını, BRCA1 mutasyonu olan tümörlerin ise BRCA2 mutasyonu olan tümörlere göre daha agresif tümörler olduğunu saptadık. Son yıllarda BRCA mutasyonu pozitif tümörlere platinyum bazlı kemoteropatik ajanların eklenmesi hem kemoterapiye cevabı hem de sağ kalımı

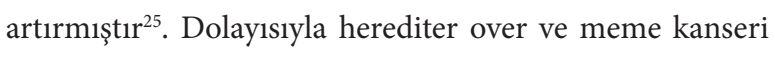
sendromunu düşündüren aile hikayesi varlığında mutlaka genetik danışmanlık istenilmeli, genetik analiz sonucuna göre hem cerrahi hem de kemoterapi tedavisi yönlendirilmelidir.

Çalışmamız Sakarya Üniversitesi Tip Fakültesi Girişimsel Olmayan Klinik Araştırmalar Etik Kurulu 29.01.2021 tarihli E-71522473-050.01.04.605836 sayılı onayı ile Helsinki Deklarasyonuna uyularak yapılmıștır. 
Sakarya Tip Dergisi 2021;11(3):647-653

ÖZDEMIR ve Ark., Herediter ve Ailesel Meme Kanserlerinin Kıyaslanması

\section{Kaynaklar}

1. Bray F, Ferlay J, Soerjomataram I, Siegel RL, Torre LA, Jemal A. Global cancer statistics 2018: GLOBOCAN estimates of incidence and mortality worldwide for 36 cancers in 185 countries [published correction appears in CA Cancer J Clin. 2020 Jul;70(4):313]. CA Cancer J Clin. 2018;68(6):394-424. doi:10.3322/caac.21492

2. Claus EB, Schildkraut J, Iversen ES Jr, Berry D, Parmigiani G. Effect of BRCA1 and BRCA2 on the association between breast cancer risk and family history. J Natl Cancer Inst. 1998;90(23):1824-1829. doi:10.1093/jnci/90.23.1824

3. Narod SA, Foulkes WD. BRCA1 and BRCA2: 1994 and beyond. Nat Rev Cancer. 2004;4(9):665-676. doi:10.1038/nrc1431

4. Venkitaraman AR. Cancer susceptibility and the functions of BRCA1 and BRCA2. Cell. 2002;108(2):171-182. doi:10.1016/s0092-8674(02)00615-3

5. Nanda R, Schumm LP, Cummings S, et al. Genetic testing in an ethnically diverse cohort of high-risk women: a comparative analysis of BRCA1 and BRCA2 mutations in American families of European and African ancestry. JAMA. 2005;294(15):1925-1933. doi:10.1001/ jama.294.15.1925

6. Comen E, Davids M, Kirchhoff T, Hudis C, Offit $K$, Robson M. Relative contributions of BRCA1 and BRCA2 mutations to "triple-negative" breast cancer in Ashkenazi Women. Breast Cancer Res Treat. 2011;129(1):185-190. doi:10.1007/s10549-011-1433-2

7. Claus EB, Schildkraut JM, Thompson WD, Risch NJ. The genetic attributable risk of breast and ovarian cancer. Cancer. 1996;77(11):2318-2324. doi:10.1002/(SICI)1097-0142(199606 01) $77: 11<2318::$ AID-CNCR21 $>3.0 . C O ; 2-Z$

8. Zweemer RP, Verheijen RH, Menko FH, et al. Differences between hereditary and sporadic ovarian cancer. Eur J Obstet Gynecol Reprod Biol. 1999;82(2):151-153. doi:10.1016/s03012115(98)00218-8

9. Cao A, Huang $L$, Shao $Z$. The Preventive Intervention of Hereditary Breast Cancer. Adv Exp Med Biol. 2017;1026:41-57. doi:10.1007/978-981-10-6020-5_3

10. Lakhani SR, Van De Vijver MJ, Jacquemier J, et al. The pathology of familial breast cancer: predictive value of immunohistochemical markers estrogen receptor, progesterone receptor, HER-2, and 553 in patients with mutations in BRCA1 and BRCA2.J Clin Oncol. 2002;20(9):2310-2318

11. Chappuis PO, Nethercot V, Foulkes WD. Clinico-pathological characteristics of BRCA1and BRCA2-related breast cancer. Semin Surg Oncol. 2000;18(4):287-295. doi:10.1002/ (sici)1098-2388(200006)18:4<287::aid-ssu3>3.0.co;2-5

12. Armes JE, Venter DJ. The pathology of inherited breast cancer. Pathology. 2002;34(4):309314. doi:10.1080/00313020220147113

13. Honrado E, Benitez J, Palacios J. The molecular pathology of hereditary breast cancer: genetic testing and therapeutic implications. Mod Pathol. 2005;18(10):1305-1320. doi:10.1038/ modpathol. 3800453
14. Daly MB, Pilarski R, Berry M, et al. NCCN Guidelines Insights: Genetic/Familial High-Risk Assessment: Breast and Ovarian, Version 2.2017. J Natl Compr Canc Netw. 2017;15(1):920. doi:10.6004/jnccn.2017.0003

15. Watson $M$, Foster $C$, Eeles $R$, et al. Psychosocial impact of breast/ovarian (BRCA1/2) cancer-predictive genetic testing in a UK multi-centre clinical cohort. Br J Cancer. 2004;91(10):1787-1794. doi:10.1038/sj.bjc.6602207

16. Botkin JR, Smith KR, Croyle RT, et al. Genetic testing for a BRCA1 mutation: prophylactic surgery and screening behavior in women 2 years post testing. Am J Med Genet A. 2003;118A(3):201-209. doi:10.1002/ajmg.a.10102

17. Evans D, Lalloo F, Shenton A, Boggis C, Howell A. Uptake of screening and prevention in women at very high risk of breast cancer. Lancet. 2001;358(9285):889-890. doi:10.1016/ S0140-6736(01)06039-1

18. Haffty BG, Harrold E, Khan AJ, et al. Outcome of conservatively managed early-onset breast cancer by BRCA1/2 status. Lancet. 2002;359(9316):1471-1477. doi:10.1016/S01406736(02)08434-9

19. Chang J, Elledge RM. Clinical management of women with genomic BRCA1 and BRCA2 mutations. Breast Cancer Res Treat. 2001;69(2):101-113. doi:10.1023/a:1012203917104

20. Foulkes WD, Chappuis PO, Wong $N$, et al. Primary node negative breast cancer in BRCA1 mutation carriers has a poor outcome. Ann Oncol. 2000;11(3):307-313. doi:10.1023/a:1008340723974

21. Van der Groep P, Bouter A, van der Zanden R, et al. Distinction between hereditary and sporadic breast cancer on the basis of clinicopathological data. J Clin Pathol. 2006;59(6):611617. doi:10.1136/jcp.2005.032151

22. Baretta Z, Mocellin S, Goldin E, Olopade OI, Huo D. Effect of BRCA germline mutation on breast cancer prognosis: A systematic review and meta-analysis. Medicine (Baltimore). 2016;95(40):e4975. doi:10.1097/MD.0000000000004975

23. Zhu Y, Wu J, Zhang $C$, et al. BRCA mutations and survival in breast cancer: an updated systematic review and meta-analysis. Oncotarget. 2016;7(43):70113-70127. doi:10.18632/ oncotarget. 12158

24. Eerola $H$, Vahteristo P, Sarantaus L, et al. Survival of breast cancer patients in BRCA1, $B R C A 2$, and non-BRCA1/2 breast cancer families: a relative survival analysis from Finland. Int J Cancer. 2001;93(3):368-372. doi:10.1002/ijc.1341

25. Tutt A, Tovey $H$, Cheang $M C U$, et al. Carboplatin in BRCA1/2-mutated and triple-negative breast cancer BRCAness subgroups: the TNT Trial. Nat Med. 2018;24(5):628-637. doi:10.1038/s41591-018-0009-7 